\title{
IMPLEMENTASI RIGID BODY PADA RIGGING TERHADAP ANIMASI DINAMIS MODEL KENDARAAN TIGA DIMENSI
}

\author{
Salam Aryanto ${ }^{1}$, Ema Utami ${ }^{2}$, Amir Fatah Sofyan ${ }^{3}$ \\ Teknik Informatika, Magister Teknik Informatika \\ Universitas Amikom Yogyakarta \\ $\underline{\text { salamori } a, \text { vahoo.com }}{ }^{1}$, emma $a$ nrar.net ${ }^{2}, \underline{\operatorname{amir} a, \text { amikom.ac.id }^{3}}$
}

\begin{abstract}
As technology grows, modeling process in three dimensions now becomes much easier than ever. But before animate a three dimensional object requires manual rigging to determine its internal frame structure. The researcher will experiment with several experimental scenarios of rigging process to produce dynamic vehicle animation by utilizing rigid body. In this case the implementation of rigid body on rigging done because rigid body very similar to object in real world. It has the force of gravity and other forces, as can collide with other objects and can push each other between objects. In particular rigging system by implementing rigid body on three dimensional vehicle model used as input will produce rigging that can be used to create mass and force so that three dimensional motion animation movement more dynamic. The results of this research indicate that the Implementation of rigid body on rigging of three dimensional vehicle model produces dynamic animation because the rigid body can be dynamically simulated with regard to contact and collision, as well as dynamically controlled objects responding to movements and collisions with other objects.
\end{abstract}

Keyword: rigid body, rigging, animation, vehicle, dynamic

\begin{abstract}
Abstrak
Semakin berkembangnya teknologi, proses pemodelan dalam tiga dimensi saat ini menjadi jauh lebih mudah dari sebelumnya. Namun sebelum menganimasikan sebuah objek tiga dimensi memerlukan rigging secara manual untuk menentukan struktur kerangka internalnya. Peneliti akan melakukan eksperimen dengan beberapa skenario percobaan terhadap proses rigging untuk menghasilkan animasi kendaraan yang dinamis dengan memanfaatkan rigid body. Dalam hal ini implementasi rigid body pada rigging dilakukan karena rigid body sangat mirip dengan objek di dunia nyata. Memiliki gaya gravitasi dan gaya lainnya, seperti bisa bertumbukan dengan objek lain dan bisa saling mendorong antar objek. Secara khusus sistem rigging dengan mengimplementasikan rigid body pada model kendaraan tiga dimensi yang digunakan sebagai masukan akan menghasilkan rigging yang dapat digunakan untuk menciptakan massa dan gaya sehingga gerakan animasi kendaraan tiga dimensi lebih dinamis. Hasil penelitian ini menunjukkan bahwa Implementasi rigid body pada rigging model kendaraan tiga dimensi menghasilkan animasi yang dinamis karena rigid body dapat disimulasikan secara dinamis berkaitan dengan kontak dan tumbukan, serta objek yang dikendalikan secara dinamis merespon gerakan dan tumbukan dengan benda lain.
\end{abstract}

Kata Kuci : rigid body, rigging, animasi, kendaraan, dinamis 


\section{Latar Belakang Masalah}

Pemodelan dalam tiga dimensi saat ini menjadi jauh lebih mudah dari sebelumnya. Namun sebelum menganimasikan sebuah objek tiga dimensi memerlukan rigging secara manual untuk menentukan struktur kerangka internalnya dan untuk menentukan bagaimana menghasilkan gerakan objek yang dinamis. Berdasarkan penelitian yang dilakukan oleh $\mathrm{Yu}$, Yang, Zan, Huang, \& Zhang, (2017) Menjelaskan bahwa dalam simulasi gerakan animasi, metode dinamis pertama-tama memberi objek pada sifat fisik dan menggunakan berbagai gaya kemudian menggunakan hukum Newton untuk melakukan kalkulasi terhadap karakteristiknya. Kegunaan metode ini adalah untuk menghitung percepatan suatu benda berdasarkan gaya yang muncul.

Berdasarkan uraian diatas peneliti akan melakukan eksperimen dengan beberapa skenario percobaan terhadap proses rigging untuk menimbulkan tumbukan, gaya, dan massa pada model kendaraan sehingga menghasilkan animasi kendaraan yang dinamis dengan memanfaatkan rigid body. Karena hasil identifikasi parameter inersia dan gaya pada objek rigid body dapat berinteraksi dengan lingkungan melalui kontak fisik. selain itu juga menunjukkan bahwa gaya (selain gaya gravitasi) dapat bekerja pada objek selama fase kontak fisik (Fazeli, Tedrake, \& Rodriguez, 2018).

Oleh karena itu penelitian ini berfokus untuk mengimplementasikan rigid body pada rigging terhadap animasi dinamis model kendaraan tiga dimensi. Pendekatan ini berfokus untuk meminimalkan kerangka kendali animasi model kendaraan tiga dimensi. Secara khusus sistem rigging dengan mengimplementasikan rigid body pada model kendaraan tiga dimensi yang digunakan sebagai masukan akan menghasilkan rigging yang dapat digunakan untuk menciptakan tumbukan, massa dan gaya sehingga gerakan animasi kendaraan tiga dimensi lebih dinamis.

\section{Landasan Teori}

\subsection{Rigging}

Rigging merupakan sebuah proses di dalam sebuah animasi dimana sebuah geometri statis ditanamkan dengan berbagai mekanisme untuk bergerak, seperti struktur kerangka yang kemudian dibungkus dengan kontrol untuk animator (Holden, Saito, \& Komura, 2015). Rigging adalah proses yang digunakan dalam komputer grafis sebagai penghubung antara modeling dan animasi. Biasanya, objek animasi dibangun dengan menggunakan serangkaian alat untuk memanipulasi geometri virtual menjadi bentuk tertentu. Ini yang umumnya dikenal sebagai modeling. Selanjutnya, tahap rigging dilakukan dan dihubungkan dengan objek geometri. Unsur-unsur ini memungkinkan animator untuk memanipulasi bentuk dan posisi objek geometri (Griffin, 2010).

\subsection{Rigid body}

Rigid body merupakan sebuah sifat material (padat, kaku, keras) dalam tiga dimensi. Rigid body yang ideal memiliki aturan yang jelas dan terdefinisi dengan baik untuk bagaimana sebuah objek bergerak di bawah aksi kekuatan dan momen, serta bagaimana batasan ideal seperti bergulir dengan sempurna, bergeser, dalam sistem pergerakan sebuah objek. Dalam hukum tumbukan inkremental, percepatan gaya rigid body dan persamaan keseimbangan momentum digunakan untuk menggambarkan dinamika selama tumbukan (Chatterjee \& Ruina, 1998). Rigid body dapat disimulasikan secara dinamis berkaitan dengan kontak dan tumbukan, serta badan yang dikendalikan secara dinamis merespon gerakan sendi dan tumbukan dengan benda lain (Weinstein, Teran, \& Fedkiw, 2006). Objek rigid body dapat berinteraksi dengan lingkungan melalui kontak fisik. selain itu juga menunjukkan bahwa gaya (selain gaya gravitasi) dapat bekerja pada objek selama fase kontak fisik (Fazeli, Tedrake, \& Rodriguez, 2018). 
Dengan adanya rigid body maka menimbulkan gerakan setelah terjadi tumbukan antar objek. Maka bisa digambarkan momen tumbukan tersebut dengan perhitungan hukum momentum yaitu hasil kali antara massa dan kecepatan. Secara matematis dapat dituliskan sebagai berikut $P=m v$ (Sheth, Lu, Yu, \& Fedkiw, 2015). Dalam peristiwa tumbukan, momentum total sistem sesaat sebelum tumbukan sama dengan momentum total sistem sesaat sesudah tumbukan.

\subsection{Animasi kendaraan}

Implementasi rigid body pada rigging model kendaraan tiga dimensi ini dilakukan untuk mengetahui apakah dengan adanya rigid body akan menghasilkan animasi yang dinamis untuk model kendaraan tiga dimensi. Karena dari hasil pengujian dengan gaya gravitasi, ada simulasi suspensi di kendaraan. Melalui simulasi mobil dan lingkungan sekitarnya dari berbagai parameter yang ditetapkan, dapat dilakukan berbagai gerakan animasi berbasis simulasi fisika (Yu et al., 2017).

\subsection{Dinamis}

Menurut Kamus Besar Bahasa Indonesia (2017) Dinamis adalah penuh semangat dan tenaga sehingga cepat bergerak dan mudah menyesuaikan diri dengan keadaan dan sebagainya; mengandung dinamika. Selanjutnya dinamika sendiri merupakan bagian ilmu fisika yang berhubungan dengan benda yang bergerak dan tenaga y ang menggerakkan.

\section{Metodologi Penelitian}

Metode penelitian yang penulis gunakan adalah eksperimental. terdapat empat prinsip dasar yang terdapat dalam desain eksperimen ini, antara lain sebagai berikut: Replication, yang merupakan pengulangan dari metode rigging dasar pada model kendaraan tiga dimensi tanpa implementasi rigid body. Selanjutnya yaitu randomization, prinsip ini digunakan pada pengujian hasil rigging yang sudah diimplementasikan rigid body dengan beberapa skenario percobaan. Pengujian ini valid bila pengamatan didistribusikan secara bebas yang dilakukan dengan pengambilan sampel secara random atau acak. Berikutnya blocking, merupakan prinsip yang digunakan untuk mengisolasi hasil yang sudah baik dan sesuai dengan indikator yang ada dari pengaruh faktor lain supaya hasil eksperimen menjadi lebih akurat. Selanjutnya yang terakhir adalah validation, merupakan suatu tindakan untuk membuktikan bahwa metode implementasi rigid body pada rigging dapat memberikan hasil yang sesuai dengan indikator keberhasilan serta memiliki keunggulan dibandingkan dengan metode lain. 


\section{Prinsip Kerja Sistem}

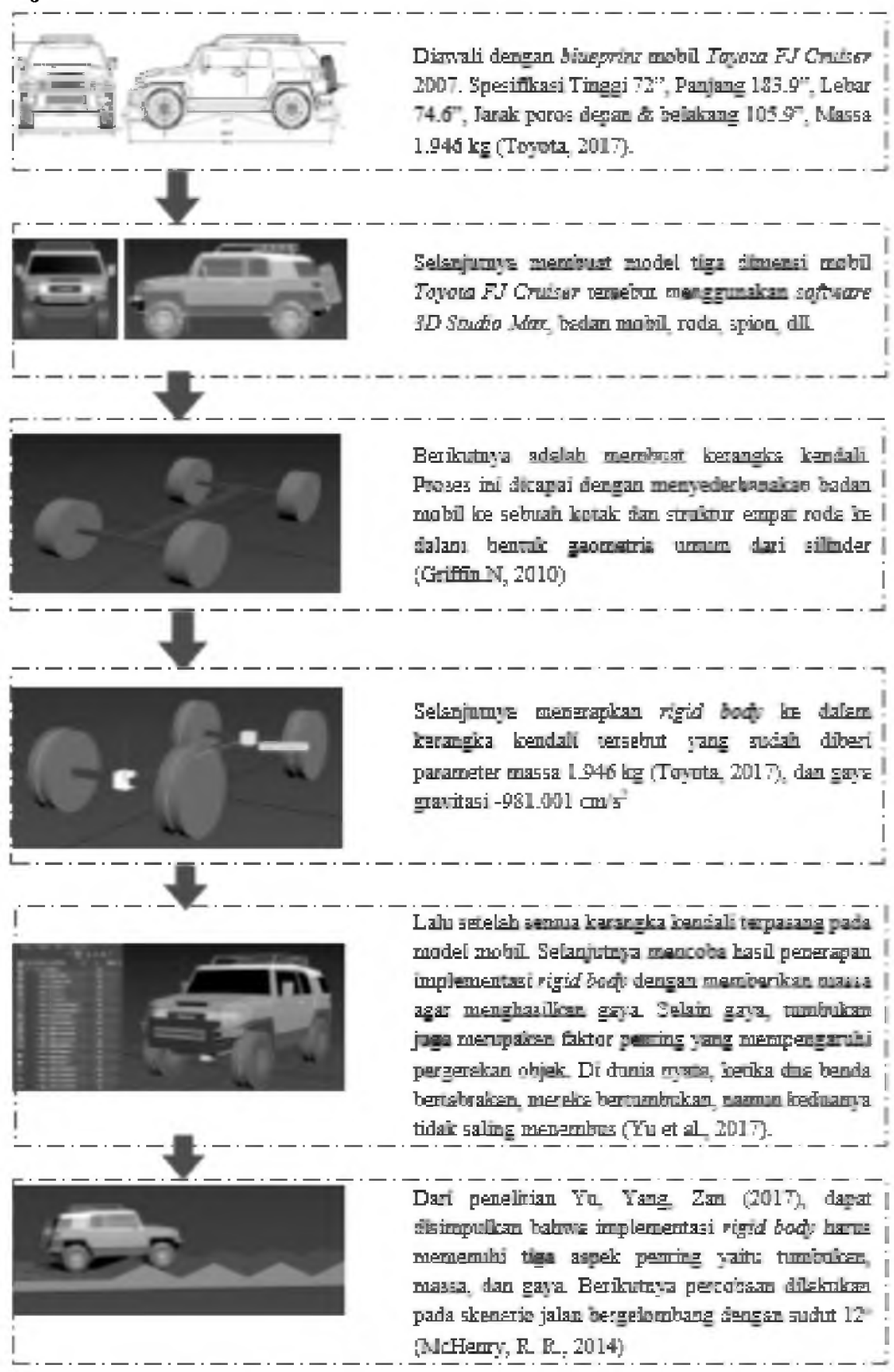

Gambar 1 Visual Olah Animasi 


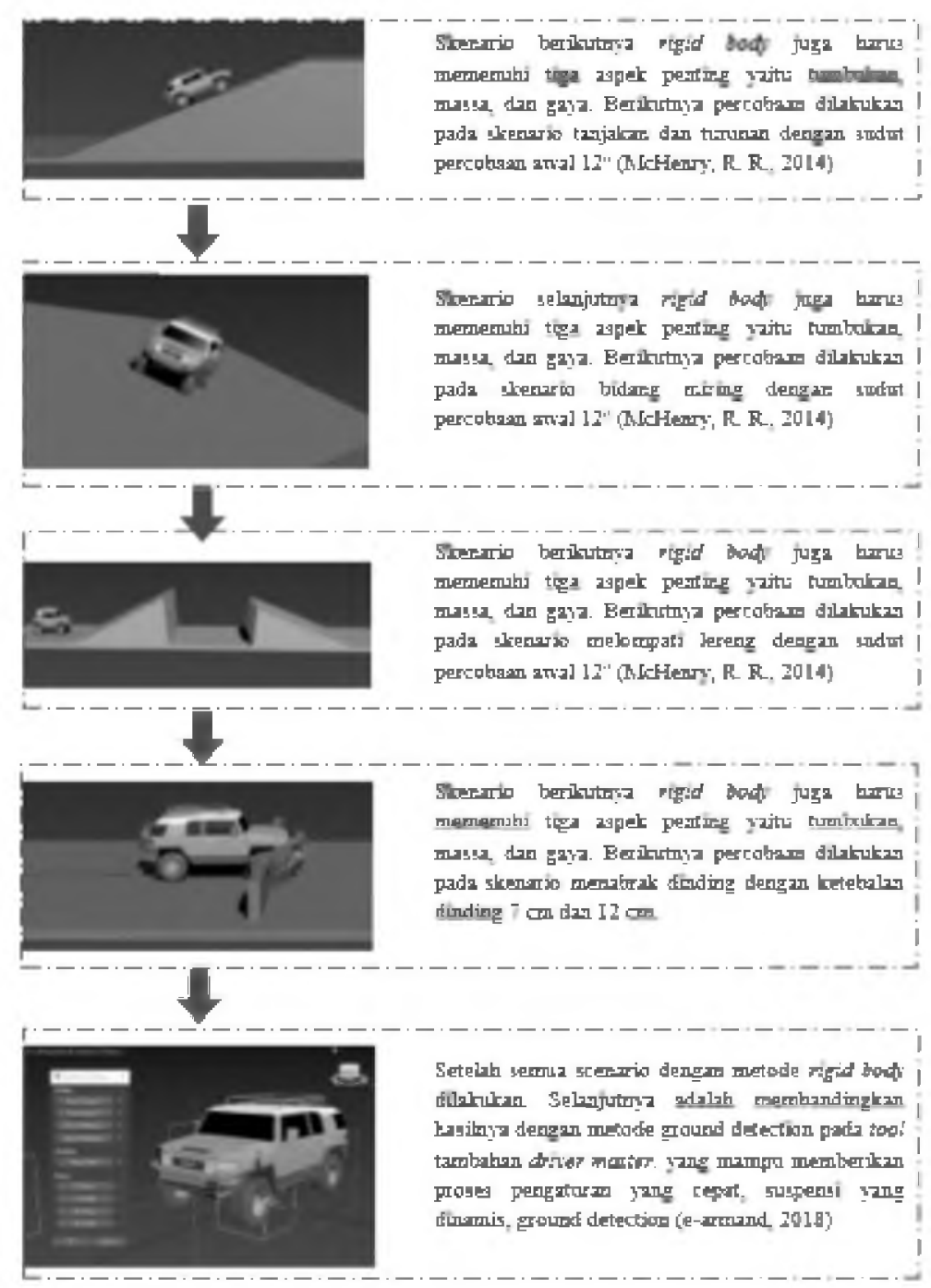

Gambar l Visual Olah Animasi (lanjutan)

Pada gambar 1 merupakan tahapan pertama dalam mengumpulkan data yang dilakukan dengan studi dari video, website, buku, jurnal nasional dan internasional. Data yang digunakan adalah model kendaraan tiga dimensi Toyota FJ Cruiser 2007. Model kendaraan tiga dimensi tersebut disesuaikan dengan data jenis, model, dan ukuran kendaraan yang sebenarnya.

Tahap selanjutnya adalah replication dimana dilakukan proses rigging model kendaraan tiga dimensi. Pada tahap ini dilakukan pemasangan kerangka dan kendali untuk menggerakkan model kendaraan. Kendali dipasang pada bagian-bagian kendali utama model kendaraan, seperti pada roda depan, roda belakang, dan badan kendaraan.

Pada tahap randomization dilakukan implementasi rigid body, yang pertama dilakukan adalah menentukan bagian-bagian model kendaraan yang bertumbukan langsung dengan lingkungan saat dilakukan uji coba. Bagian-bagian tersebut meliputi roda depan, roda belakang, dan badan kendaraan. Dimana roda depan dan belakang bertumbukan langsung dengan permukaan landasan tempat model kendaraan berjalan. Selanjutnya badan model kendaraan bertumbukan dengan dinding saat proses uji coba.

Untuk blocking dilakukan analisis terhadap gerakan animasi dinamis model kendaraan tiga dimensi dilakukan beberapa skenario percobaan. Skenario tersebut dipilih berdasarkan 
penelitian tentang simulasi kendaraan dinamis oleh McHenry (2014). Di dalam penelitiannya dijelaskan bahwa ada beberapa uji coba untuk mengetahui suatu kendaraan dikatakan dinamis yaitu : single vehicle accident; misalnya bergerak di jalan bergelombang, ramp to ramp, berjalan di bidang miring, tanjakan dan turunan, dan menabrak dinding. fokus utama yang diperhatikan disesuaikan dengan latar belakang masalah dalam penelitian ini yaitu massa dan gaya yang ditimbulkan model kendaraan tiga dimensi tersebut saat dianimasikan. Artinya dengan adanya perbedaan massa yang dimasukkan ke dalam rigid body pada model kendaraan maka menghasilkan gaya yang berbeda. Dengan adanya massa maka deteksi tumbukan antar objek mempengaruhi dinamika gerakan animasi pada model kendaraan tiga dimensi. Oleh karena itu dilakukan berbagai percobaan pengaturan secara random pada rigid body agar setiap gerakan bisa memenuhi indikator keberhasilan animasi dinamis.

\section{Hasil dan Pembahasan}

\subsection{Skenario Jalan Bergelombang}

Pada bagian rig badan kendaraan juga diberikan penghubung agar saat terjadi pergerakan pada model kendaraan, setiap bagian dari kendaraan tersebut tidak terpisah. Dalam hal ini antara rig badan mobil dengan rig center harus diberi penghubung diantara objek rigid. Berikut gambar 2 yang menunjukkan proses menghubungkan rig badan mobil dengan rig center.
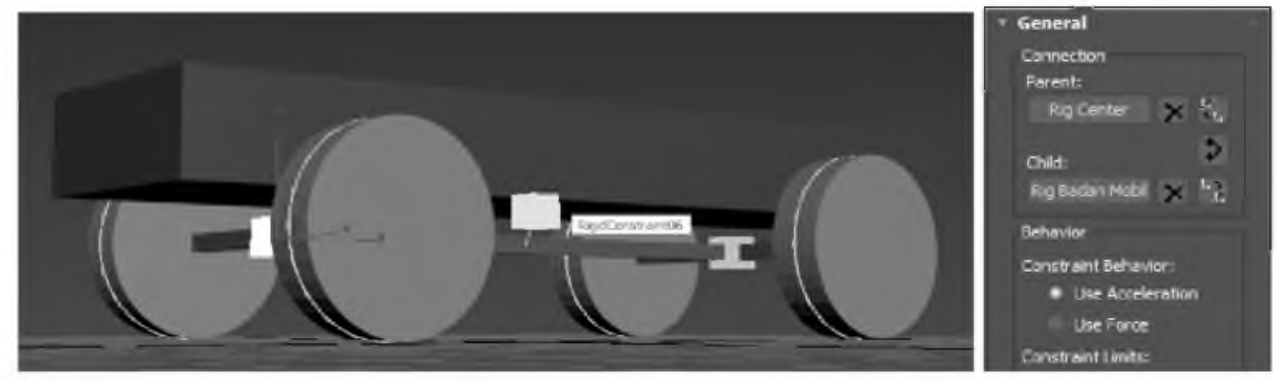

Gambar 2 Implementasi Rigid Body Badan Kendaraan

Berikut gambar 3 yang menunjukkan hasil keseluruhan dari setiap proses rigging dan implementasi rigid body. Pada gambar tersebut terlihat jelas keseluruhan bagian serta daftar bagian-bagian model, bagian rigging, dan bagian dari implementasi rigid body yang menempel pada model kendaraan.

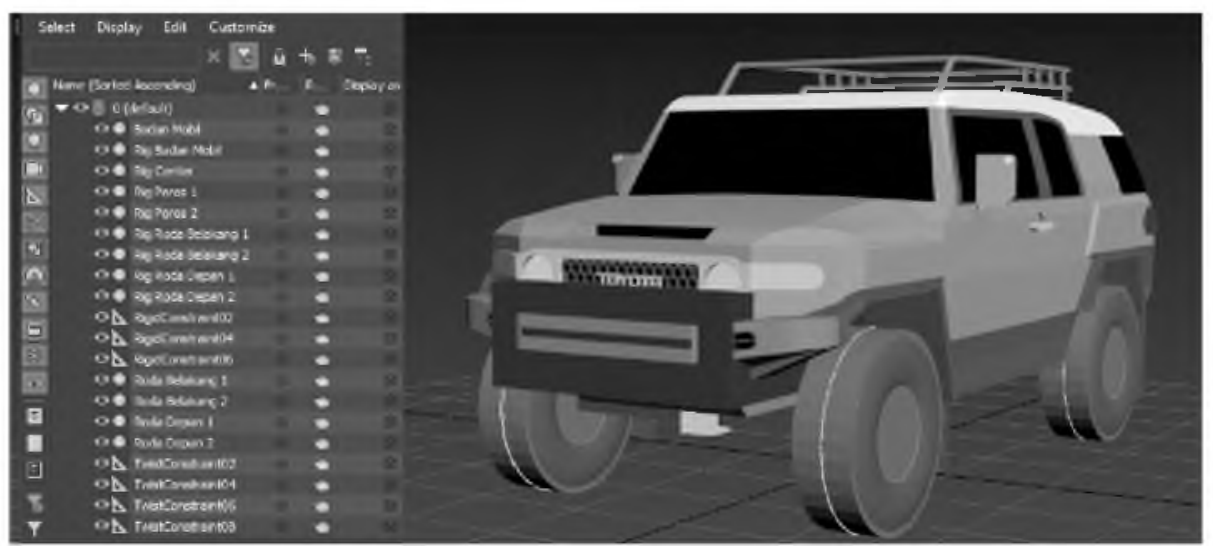

Gambar 3 Implementasi Rigid Body Model Kendaraan 
Untuk menghasilkan jarak tumbukan antara lintasan dengan model kendaraan yang baik maka dilakukan eksperimen dengan merubah parameter dari solver iteration, ditunjukkan pada gambar 4. Dimana parameter ini merupakan pengaturan toleransi jarak tumbukan yang terjadi diatara dua buah objek rigid. Angka yang semakin besar akan sangat berguna pada objek dengan rangkaian yang saling terhubung.

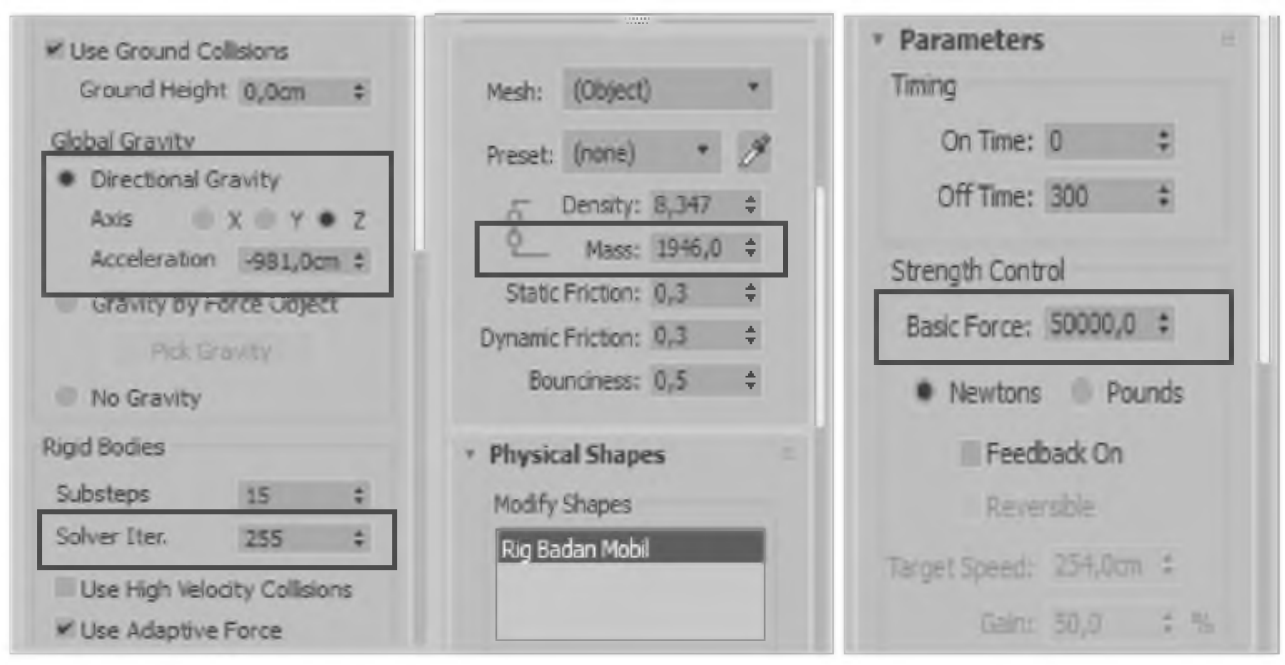

Gambar 4 Parameter Gravitasi, Massa, dan Toleransi Tumbukan

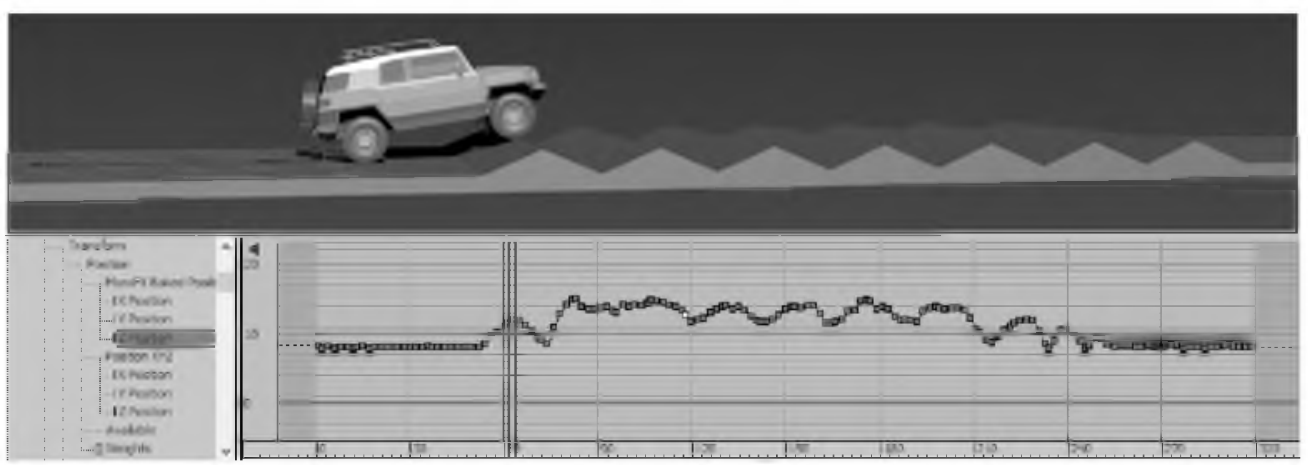

Gambar 5 Skenario Jalan Bergelombang

Tabel 1 Perbandingan Koordinat Lintasan dan Gerakan Kendaran

\begin{tabular}{|c|c|c|c|}
\hline Key Frame & $\begin{array}{c}\text { Koordinat } \\
\text { Lintasan }\end{array}$ & $\begin{array}{c}\text { Koordinat } \\
\text { Kendaraan }\end{array}$ & Selisish \\
\hline Frame 30 & $8 \mathrm{~cm}$ & $7,995 \mathrm{~cm}$ & $0,005 \mathrm{~cm}$ \\
\hline Frame 60 & $12 \mathrm{~cm}$ & $11,833 \mathrm{~cm}$ & $0,167 \mathrm{~cm}$ \\
\hline Frame 90 & $14 \mathrm{~cm}$ & $13,626 \mathrm{~cm}$ & $0,374 \mathrm{~cm}$ \\
\hline Frame 120 & $12 \mathrm{~cm}$ & $11,693 \mathrm{~cm}$ & $0,307 \mathrm{~cm}$ \\
\hline Frame 150 & $14 \mathrm{~cm}$ & $13,672 \mathrm{~cm}$ & $0,328 \mathrm{~cm}$ \\
\hline Frame 180 & $14 \mathrm{~cm}$ & $13,796 \mathrm{~cm}$ & $0,204 \mathrm{~cm}$ \\
\hline Frame 210 & $12 \mathrm{~cm}$ & $11,353 \mathrm{~cm}$ & $0,647 \mathrm{~cm}$ \\
\hline Frame 240 & $12 \mathrm{~cm}$ & $10,488 \mathrm{~cm}$ & $1,512 \mathrm{~cm}$ \\
\hline Frame 270 & $8 \mathrm{~cm}$ & $7,900 \mathrm{~cm}$ & $0,100 \mathrm{~cm}$ \\
\hline & & Rata $-\mathrm{rata}$ & $0,405 \mathrm{~cm}$ \\
\hline
\end{tabular}

Pada tabel 1 menunjukkan hasil untuk setiap frame gerakan animasi pada model kendaraan tiga dimensi sudah terjadi tumbukan. Dimana dalam tabel tersebut sudah ada 
implementasi rigid body pada model kendaraan. Hal tersebut ditunjukkan pada koordinat kendaraan yang berubah mengikuti koordinat lintasan. Untuk hasil koordinat kendaraan yang ditunjukkan dalam tabel tidak sama persis dengan angka yang ditunjukkan pada koordinat lintasan. Hal ini disebabkan adanya gerakan naik turun dari suspensi yang bekerja pada model kendaraan tiga dimensi.

\subsection{Skenario Tanjakan dan Turunan}

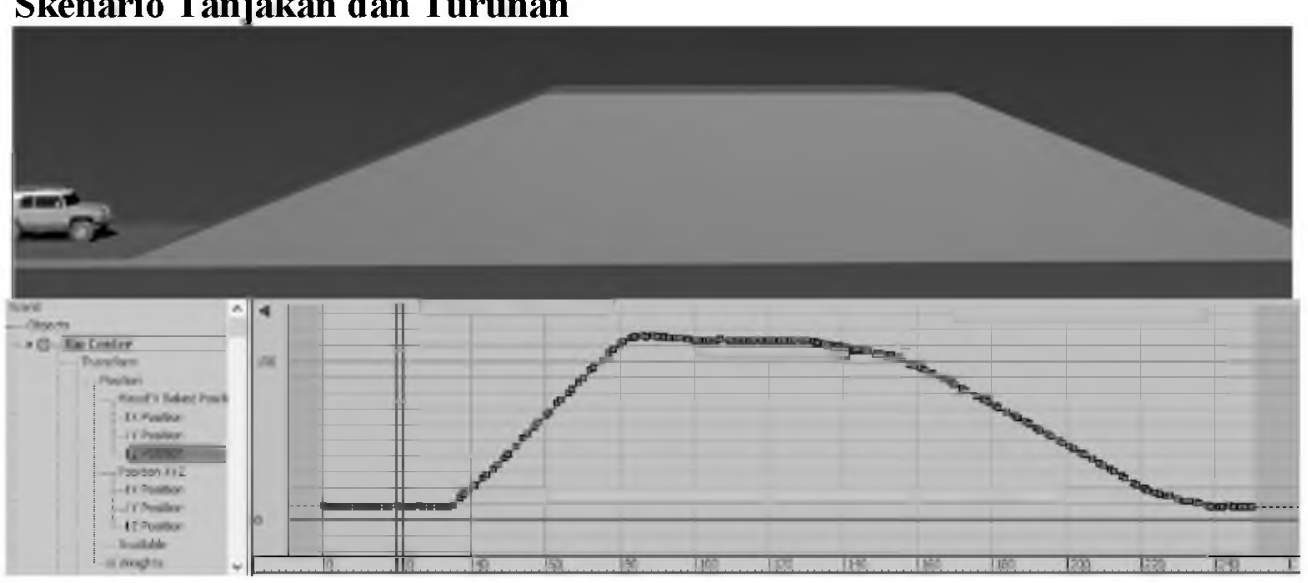

Gambar 6 Skenario Tanjakan dan Turunan

Tabel 2 Perbandingan Koordinat Lintasan dan Gerakan Kendaran

\begin{tabular}{|c|c|c|c|}
\hline Key Frame & $\begin{array}{c}\text { Koordinat } \\
\text { Lintasan }\end{array}$ & $\begin{array}{c}\text { Koordinat } \\
\text { Kendaraan }\end{array}$ & Selisish \\
\hline Frame 20 & $9 \mathrm{~cm}$ & $8,154 \mathrm{~cm}$ & $0,846 \mathrm{~cm}$ \\
\hline Frame 40 & $22 \mathrm{~cm}$ & $21,432 \mathrm{~cm}$ & $0.568 \mathrm{~cm}$ \\
\hline Frame 60 & $68 \mathrm{~cm}$ & $67,712 \mathrm{~cm}$ & $0,288 \mathrm{~cm}$ \\
\hline Frame 80 & $112 \mathrm{~cm}$ & $111,917 \mathrm{~cm}$ & $0,083 \mathrm{~cm}$ \\
\hline Frame 100 & $114 \mathrm{~cm}$ & $113,174 \mathrm{~cm}$ & $0,826 \mathrm{~cm}$ \\
\hline Frame 120 & $114 \mathrm{~cm}$ & $113,082 \mathrm{~cm}$ & $0,918 \mathrm{~cm}$ \\
\hline Frame 140 & $110 \mathrm{~cm}$ & $108,224 \mathrm{~cm}$ & $1,776 \mathrm{~cm}$ \\
\hline Frame 160 & $96 \mathrm{~cm}$ & $95,657 \mathrm{~cm}$ & $0,343 \mathrm{~cm}$ \\
\hline Frame 180 & $72 \mathrm{~cm}$ & $71,946 \mathrm{~cm}$ & $0,054 \mathrm{~cm}$ \\
\hline Frame 200 & $46 \mathrm{~cm}$ & $45,964 \mathrm{~cm}$ & $0,036 \mathrm{~cm}$ \\
\hline Frame 220 & $18 \mathrm{~cm}$ & $17,807 \mathrm{~cm}$ & $0,193 \mathrm{~cm}$ \\
\hline Frame 240 & $9 \mathrm{~cm}$ & $8,043 \mathrm{~cm}$ & $0,957 \mathrm{~cm}$ \\
\hline & & Rata $-\mathrm{rata}$ & $0,574 \mathrm{~cm}$ \\
\hline
\end{tabular}

Pada tabel 2 menunjukkan hasil untuk setiap frame gerakan animasi pada model kendaraan tiga dimensi sudah terjadi tumbukan. Dimana dalam tabel tersebut sudah ada implementasi rigid body pada model kendaraan. Hal tersebut ditunjukkan pada koordinat kendaraan yang berubah mengikuti koordinat lintasan. Untuk hasil koordinat kendaraan yang ditunjukkan dalam tabel tidak sama persis dengan angka yang ditunjukkan pada koordinat lintasan. Hal ini disebabkan adanya gerakan naik turun dari suspensi yang bekerja pada model kendaraan tiga dimensi. 


\subsection{Skenario Bidang Miring}

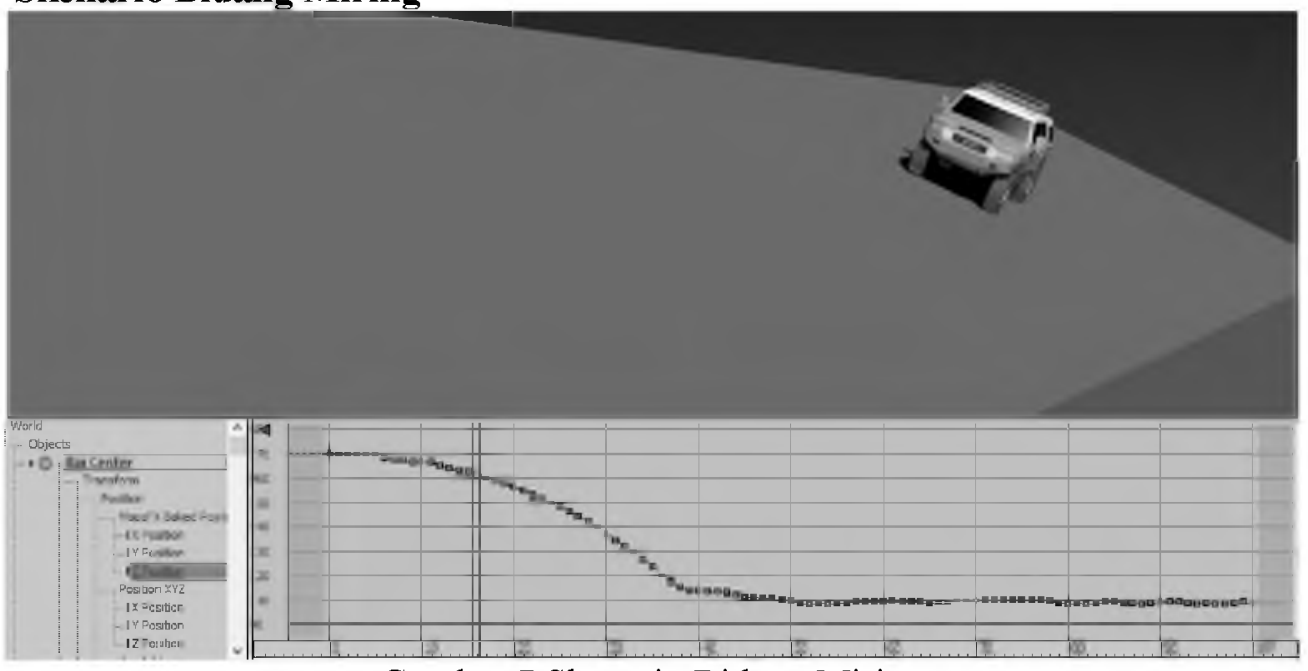

Gambar 7 Skenario Bidang Miring

Tabel 3 Perbandingan Koordinat Lintasan dan Gerakan Kendaran

\begin{tabular}{|c|c|c|c|}
\hline Key Frame & Koordinat Lintasan & $\begin{array}{c}\text { Koordinat } \\
\text { Kendaraan }\end{array}$ & Selisih \\
\hline Frame 10 & $67 \mathrm{~cm}$ & $66,401 \mathrm{~cm}$ & $0,599 \mathrm{~cm}$ \\
\hline Frame 20 & $57 \mathrm{~cm}$ & $56,165 \mathrm{~cm}$ & $0,835 \mathrm{~cm}$ \\
\hline Frame 30 & $37 \mathrm{~cm}$ & $36,811 \mathrm{~cm}$ & $0,189 \mathrm{~cm}$ \\
\hline Frame 40 & $14 \mathrm{~cm}$ & $13,440 \mathrm{~cm}$ & $0,560 \mathrm{~cm}$ \\
\hline Frame 50 & $10 \mathrm{~cm}$ & $9,134 \mathrm{~cm}$ & $0,866 \mathrm{~cm}$ \\
\hline Frame 60 & $9 \mathrm{~cm}$ & $8,959 \mathrm{~cm}$ & $0,041 \mathrm{~cm}$ \\
\hline \multicolumn{2}{|c|}{} & Rata - rata & $0,515 \mathrm{~cm}$ \\
\hline
\end{tabular}

Pada tabel 3 menunjukkan hasil untuk setiap frame gerakan animasi pada model kendaraan tiga dimensi sudah terjadi tumbukan. Dimana dalam tabel tersebut sudah ada implementasi rigid body pada model kendaraan. Hal tersebut ditunjukkan pada koordinat kendaraan yang berubah mengikuti koordinat lintasan. Untuk hasil koordinat kendaraan yang ditunjukkan dalam tabel tidak sama persis dengan angka yang ditunjukkan pada koordinat lintasan. Hal ini disebabkan adanya gerakan naik turun dari suspensi yang bekerja pada model kendaraan tiga dimensi.

\subsection{Skenario Ramp To Ramp}

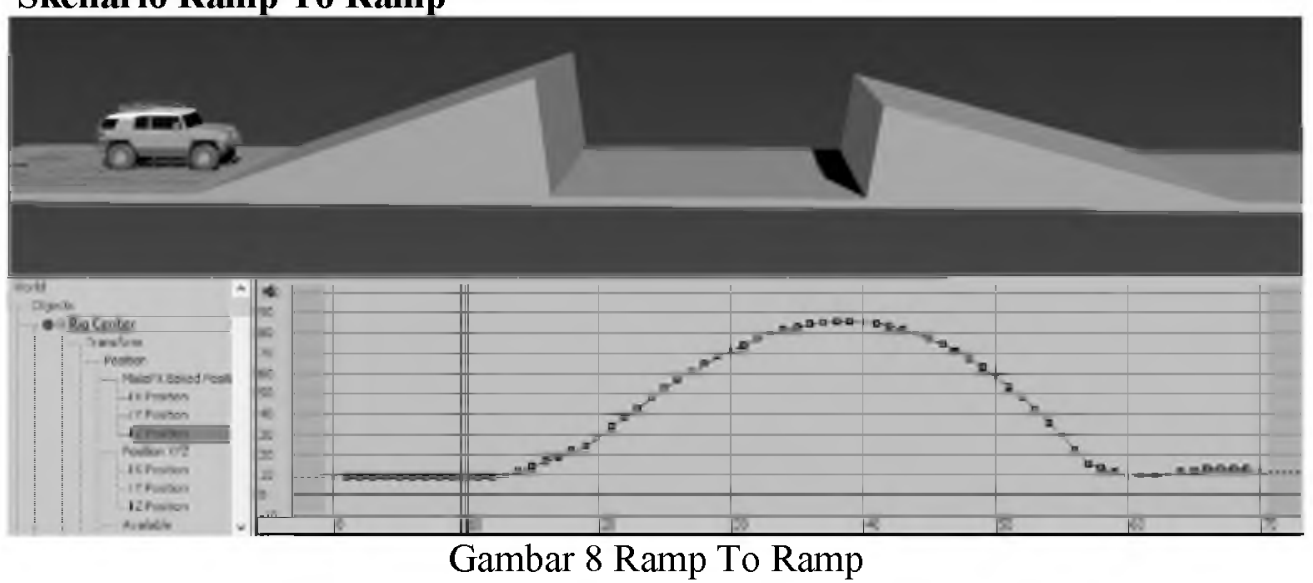


Tabel 4 Perbandingan Koordinat Lintasan dan Gerakan Kendaran

\begin{tabular}{|c|c|c|c|}
\hline Key Frame & Koordinat Lintasan & $\begin{array}{c}\text { Koordinat } \\
\text { Kendaraan }\end{array}$ & Selisih \\
\hline Frame 10 & $9 \mathrm{~cm}$ & $8,033 \mathrm{~cm}$ & $0,967 \mathrm{~cm}$ \\
\hline Frame 20 & $29 \mathrm{~cm}$ & $28,298 \mathrm{~cm}$ & $0,702 \mathrm{~cm}$ \\
\hline Frame 30 & $71 \mathrm{~cm}$ & $70,640 \mathrm{~cm}$ & $0,36 \mathrm{~cm}$ \\
\hline Frame 40 & $85 \mathrm{~cm}$ & $84,866 \mathrm{~cm}$ & $0,134 \mathrm{~cm}$ \\
\hline Frame 50 & $58 \mathrm{~cm}$ & $57,890 \mathrm{~cm}$ & $0,11 \mathrm{~cm}$ \\
\hline Frame 60 & $9 \mathrm{~cm}$ & $8,706 \mathrm{~cm}$ & $0,294 \mathrm{~cm}$ \\
\hline \multicolumn{2}{|r|}{} & Rata - rata & $0,43 \mathrm{~cm}$ \\
\hline
\end{tabular}

Pada tabel 4 menunjukkan hasil untuk setiap frame gerakan animasi pada model kendaraan tiga dimensi sudah terjadi tumbukan. Dimana dalam tabel tersebut sudah ada implementasi rigid body pada model kendaraan. Hal tersebut ditunjukkan pada koordinat kendaraan yang berubah mengikuti koordinat lintasan. Untuk hasil koordinat kendaraan yang ditunjukkan dalam tabel tidak sama persis dengan angka yang ditunjukkan pada koordinat lintasan. Hal ini disebabkan adanya gerakan naik turun dari suspensi yang bekerja pada model kendaraan tiga dimensi.

\subsection{Skenario Menabrak Dinding}

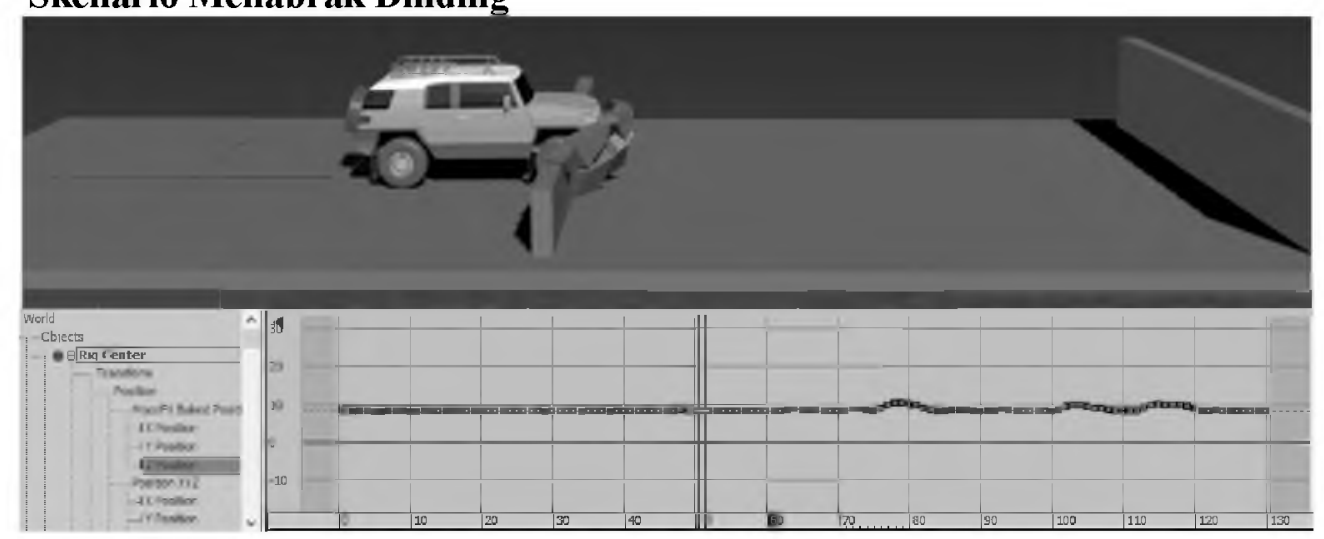

Gambar 9 Menabrak Dinding

Tabel 5 Perbandingan Koordinat Lintasan dan Gerakan Kendaran

\begin{tabular}{|c|c|c|c|}
\hline Key Frame & Koordinat Lintasan & $\begin{array}{c}\text { Koordinat } \\
\text { Kendaraan }\end{array}$ & Selisih \\
\hline Frame 10 & $8 \mathrm{~cm}$ & $7,906 \mathrm{~cm}$ & $0,91 \mathrm{~cm}$ \\
\hline Frame 20 & $8 \mathrm{~cm}$ & $7,906 \mathrm{~cm}$ & $0,91 \mathrm{~cm}$ \\
\hline Frame 30 & $8 \mathrm{~cm}$ & $7,906 \mathrm{~cm}$ & $0,91 \mathrm{~cm}$ \\
\hline Frame 40 & $8 \mathrm{~cm}$ & $7,906 \mathrm{~cm}$ & $0,91 \mathrm{~cm}$ \\
\hline Frame 50 & $8 \mathrm{~cm}$ & $7,906 \mathrm{~cm}$ & $0,91 \mathrm{~cm}$ \\
\hline Frame 60 & $8 \mathrm{~cm}$ & $7,906 \mathrm{~cm}$ & $0,91 \mathrm{~cm}$ \\
\hline Frame 70 & $8 \mathrm{~cm}$ & $8,045 \mathrm{~cm}$ & $0,045 \mathrm{~cm}$ \\
\hline Frame 80 & $8 \mathrm{~cm}$ & $10,168 \mathrm{~cm}$ & $2,168 \mathrm{~cm}$ \\
\hline Frame 90 & $8 \mathrm{~cm}$ & $7,856 \mathrm{~cm}$ & $0,144 \mathrm{~cm}$ \\
\hline Frame 100 & $8 \mathrm{~cm}$ & $7,937 \mathrm{~cm}$ & $0,063 \mathrm{~cm}$ \\
\hline Frame 110 & $8 \mathrm{~cm}$ & $8,173 \mathrm{~cm}$ & $0,173 \mathrm{~cm}$ \\
\hline \multicolumn{2}{|r|}{} & Rata $-\mathrm{rata}$ & $0,73 \mathrm{~cm}$ \\
\hline
\end{tabular}


Pada tabel 5 menunjukkan hasil untuk setiap frame gerakan animasi pada model kendaraan tiga dimensi sudah terjadi tumbukan. Dimana dalam tabel tersebut sudah ada implementasi rigid body pada model kendaraan. Hal tersebut ditunjukkan pada koordinat kendaraan yang berubah mengikuti koordinat lintasan.. Untuk hasil koordinat kendaraan yang ditunjukkan dalam tabel tidak sama persis dengan angka yang ditunjukkan pada koordinat lintasan. Hal ini disebabkan adanya gerakan naik turun dari suspensi yang bekerja pada model kendaraan tiga dimensi.

Tabel 6 Rata - Rata Jarak Tumbukan Lintasan dengan Kendaraan

\begin{tabular}{|l|c|c|}
\hline \multirow{2}{*}{ Skenario } & \multicolumn{2}{|c|}{ Rata - Rata Jarak Lintasan dengan Kendaraan } \\
\cline { 2 - 3 } & $\begin{array}{c}\text { Sebelum Implementasi } \\
\text { Rigid Body }\end{array}$ & $\begin{array}{c}\text { Sesudah Implementasi } \\
\text { Rigid Body }\end{array}$ \\
\hline Jalan Bergelombang & $4,44 \mathrm{~cm}$ & $0,405 \mathrm{~cm}$ \\
\hline Tanjakan dan Turunan & $56,83 \mathrm{~cm}$ & $0,574 \mathrm{~cm}$ \\
\hline Bidang Miring & $13,76 \mathrm{~cm}$ & $0,515 \mathrm{~cm}$ \\
\hline Ramp to Ramp & $35,5 \mathrm{~cm}$ & $0,43 \mathrm{~cm}$ \\
\hline Menabrak Dinding & $0 \mathrm{~cm}$ & $0,73 \mathrm{~cm}$ \\
\hline
\end{tabular}

Pada tabel 6 dapat dilihat bahwa pada skenario jalan bergelombang, tanjakan dan turunan, bidang miring, ramp to ramp memiliki jarak lintasan dengan kendaraan sebelum implementasi rigid body menghasilkan nilai yang sangat besar dikarenakan tidak ada tumbukan sama sekali sedangkan sesudah implementasi rigid body menghasilkan nilai yang kecil untuk jarak antara lintasan dengan model kendaraan. Namun berbeda pada skenario saat kendaraan menabrak dinding. Sebelum implementasi menghasilkan nilai 0 dikarenakan model kendaraan hanya bergerak datar menembus dinding tanpa adanya tumbukan dengan objek dinding. Sedangkan sesudah implementasi rigid body justru menghasilkan angka yang lebih besar. Hal tersebut dikarenakan setelah model kendaraan menabrak dinding terjadi tumbukan lain antara model kendaraan dengan pecahan dinding.

\section{Kesimpulan Dan Saran}

\subsection{Kesimpulan}

Berdasarkan hasil penelitian ini, dapat disimpulkan beberapa hal mengenai Implementasi Rigid body Pada Rigging Terhadap Animasi Dinamis Model Kendaraan Tiga Dimensi.

1. Untuk menghasilkan animasi model kendaraan tiga dimensi yang dinamis diperlukan implementasi rigid body agar menghasilkan tumbukan, massa, dan gaya pada objek tiga dimensi. Adapun proses yang dilakukan :

- Rigid body pada kendaraan diberikan parameter agar memenuhi tiga aspek penting pada animasi dinamis yaitu massa $=1946 \mathrm{~kg}$ dan gaya gravitasi $=-981.001 \mathrm{~cm} / \mathrm{s}^{2}$

- Menghasilkan gerakan model kendaraan tiga dimensi yang sesuai dengan koordinat lintasan yang dilalui. Artinya jarak tumbukan antara lintasan dengan model kendaraan sangat kecil atau sama dengan 0 .

2. Dari setiap skenario percobaan pada rigging terhadap model kendaraan tiga dimensi memberikan hasil gerakan animasi yang dinamis pada model kendaraan untuk setiap skenario lingkungan yang berbeda. Adapun perubahan koordinat pada kurva, menunjukkan perubahan pada sumbu $\mathrm{Z}$ sesuai dengan bentuk jalan yang dilalui model kendaraan.

3. Implementasi rigid body pada rigging terhadap animasi dinamis model kendaraan tiga dimensi memberikan hasil gerakan animasi yang dinamis. 
4. seperti terjadi tumbukan antara objek rigid, gerakan model kendaraan mengikuti bentuk permukaan jalan karena adanya massa dan gaya gravitasi. Selain itu meminimalkan kerangka kendali pada model kendaraan untuk menghasilkan gerakan animasi.

\subsection{Saran}

Untuk penelitian berikutnya sebaiknya melakukan skenario percobaan yang lebih spesifik, seperti material jalan yang dilalui. Melakukan perhitungan untuk gerakan animasi yang akan dihasilkan, serta analisis penilaian hasil gerakan animasi yang lebih akurat.

\section{Daftar Pustaka}

Chatterjee, A., \& Ruina, A. (1998). Two Interpretations of Rigidity in Rigid-Body Collisions. Journal of Applied Mechanics, 65(4), 894-900. https://doi.org/ 10.1115/1.2791929

Fazeli, N., Tedrake, R., \& Rodriguez, A. (2018). Identifiability Analysis of Planar RigidBody Frictional Contact. In Robotics Research (pp. 665-682). Springer, Cham. httos://doi.org/10.1007/978-3-319-60916-4 38

Griffin, N., (2010). Retrieved from http://oaktrust.library.tamu.edu/ bitstream/ handle/1969.1/ETD-TAMU-2010-128857/GRIFFINTHESIS.pdf

McHenry, R. R. (2014). The Role of Vehicle Dynamics Simulation in Highway Safety Research . ASME 16th International Conference on Advanced Vehicle Technologies, $1-16$.

Sheth, R., Lu, W., Yu, Y., \& Fedkiw, R. (2015). Fully Momentum-conserving Reduced Deformable Bodies with Collision, Contact, Articulation, and Skinning. In Proceedings of the 14th ACM SIGGRAPH / Eurographics Symposium on Computer Animation (pp. 45-54). New York, NY, USA: ACM. https://doi.org/10.1145/2786784.2786787

Yu, Y., Yang, J., Zan, X., Huang, J., \& Zhang, X. (2017). Research of Simulation in Character Animation Based on Physics Engine [Research article]. https://doi.org/10.1155/2017/4815932 